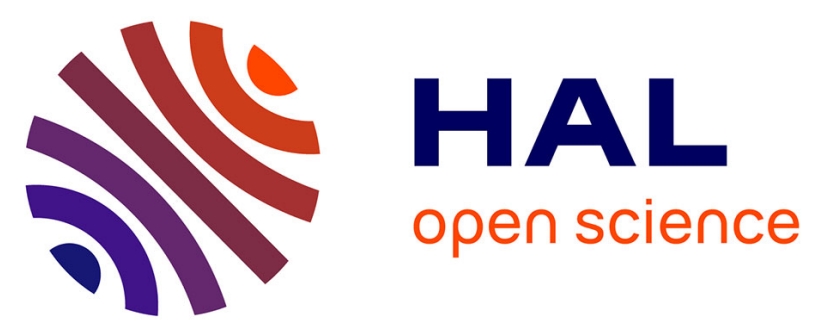

\title{
Drug survival and postdrug survival of first-line immunosuppressive treatments for atopic dermatitis comparison between methotrexate and cyclosporine
}

Sarah Law Ping Man, Guillaume Bouzillé, Nathalie Beneton, Gilles Safa, Alain Dupuy, Catherine Droitcourt

\section{To cite this version:}

Sarah Law Ping Man, Guillaume Bouzillé, Nathalie Beneton, Gilles Safa, Alain Dupuy, et al.. Drug survival and postdrug survival of first-line immunosuppressive treatments for atopic dermatitis comparison between methotrexate and cyclosporine. Journal of the European Academy of Dermatology and Venereology, 2018, 32 (8), pp.1327-1335. 10.1111/jdv.14880 . hal-01798651

HAL Id: hal-01798651

https://hal-univ-rennes1.archives-ouvertes.fr/hal-01798651

Submitted on 20 Sep 2018

HAL is a multi-disciplinary open access archive for the deposit and dissemination of scientific research documents, whether they are published or not. The documents may come from teaching and research institutions in France or abroad, or from public or private research centers.
L'archive ouverte pluridisciplinaire HAL, est destinée au dépôt et à la diffusion de documents scientifiques de niveau recherche, publiés ou non, émanant des établissements d'enseignement et de recherche français ou étrangers, des laboratoires publics ou privés. 


\section{Drug survival and post-drug survival of first-line immunosuppressive treatments for atopic dermatitis: comparison between methotrexate and cyclosporine.}

Sarah Law Ping Man ${ }^{1,2}$, MD; Guillaume Bouzillé 3,4,5,6 $^{\text {MD; Nathalie Beneton }}{ }^{7}$, MD; Gilles $\mathrm{Safa}^{8}, \mathrm{MD}$; Alain Dupuy ${ }^{1,2,9 *}, \mathrm{MD}, \mathrm{PhD}$; Catherine Droitcourt ${ }^{1,2,6,9}, \mathrm{MD}$

\section{Affiliations:}

${ }^{1}$ University Rennes 1, Rennes, France

${ }^{2}$ Department of Dermatology, CHU Rennes, France

${ }^{3}$ INSERM U1099, Rennes, France

${ }^{4}$ University Rennes 1, LTSI, Rennes, France

${ }^{5}$ Clinical Data Center CHU Rennes, France

${ }^{6}$ INSERM CIC 1414, Rennes, France

${ }^{7}$ Department of Dermatology, CH Le Mans, France

${ }^{8}$ Department of Dermatology, CH Saint-Brieuc, France

9 UPRES EA 7449 REPERES Pharmaco-Epidemiology and Health Services Research, University Rennes 1 and French School of Public Health, Rennes, France

*Equal contribution

Address correspondence to: Dr DROITCOURT Catherine, Department of Dermatology, Pontchaillou Hospital, 2 rue Henri le Guilloux 35000 Rennes, France, Tel: + 332992843 49, Fax: + 332992841 00, Mailto: catherine.droitcourt@chu-rennes.fr

Key Words: atopic dermatitis, immunosuppressive treatment, drug survival, post-drug survival

Conflicts of interest: None to declare

Funding sources: None

Running head: Drug survival and post-drug survival of immunosuppressive treatments for atopic dermatitis

This article has been accepted for publication and undergone full peer review but has not been through the copyediting, typesetting, pagination and proofreading process, which may lead to differences between this version and the Version of Record. Please cite this article as doi: 


\title{
ABBREVIATIONS
}

AD: Atopic dermatitis

MTX: Methotrexate

CYC: Cyclosporine

\begin{abstract}
Introduction: Cyclosporine and methotrexate are the two preferred first-line immunosuppressive treatments in atopic dermatitis. The aim of this study was to compare the treatment profiles of methotrexate and cyclosporine in daily practice as the first-line immunosuppressive treatment in atopic dermatitis, using two survival analyses, "drug survival" (time on the drug) and "post-drug survival" (time between two drugs).

Methods: Retrospective study including patients with moderate-to-severe atopic dermatitis treated with methotrexate or cyclosporine as the first-line immunosuppressive treatment. The reasons for discontinuation of treatment were collected: controlled disease, treatment failure, side event pregnancy and non-compliance. "Drug survival" and "post-drug survival" analyses were performed using the Kaplan Meier method and predictive factors were analyzed using uni- and multivariate Cox regression analyses.
\end{abstract}

Results: 56 patients, among whom 25 patients treated with cyclosporine and 31 with methotrexate (median age: $34 \pm 15$ years) were included between 2007 and 2016. Reasons for discontinuation were not significantly different between "controlled disease" and other reasons $(p=0.11)$. The median "drug survival" was significantly longer for methotrexate (23 months) than for cyclosporine $(8$ months $)(p<0.0001)$. Six months from baseline, $93 \%$ of patients treated with methotrexate were still being treated $v_{s} 63 \%$ among patients treated with cyclosporine. The median of "post-drug survival" was significantly longer for methotrexate (12 months) than for cyclosporine (2 months). Only treatment with CYC was a predictive factor for decreased "drug survival" and "post-drug survival".

Conclusion: This is the first direct comparison between methotrexate and cyclosporine as first-line immunosuppressive treatments for moderate to severe atopic dermatitis in daily practice. We evidenced two different treatment profiles: the duration of methotrexate administration is longer than that of cyclosporine. "Post-drug survival" could be a new tool to 
assess the maintenance of effect of a drug after withdrawal in atopic dermatitis, and more broadly in chronic skin disease.

\section{INTRODUCTION}

Atopic dermatitis (AD) is one of the most common chronic inflammatory skin diseases in both children and adults with a prevalence of 10 to $20 \%{ }^{1,2}$.

In most of cases, AD patients are mainly managed in primary care with the following treatment strategies: daily emollient application, use of anti-inflammatory topical therapy including topical steroids and topical calcineurin inhibitors and avoidance of individual triggering factors for mild $\mathrm{AD}$, and conventional topical anti-inflammatory therapy with a proactive approach and phototherapy for moderate $\mathrm{AD}$. In the more severe $\mathrm{AD}$ patients i.e patients with chronic active disease or subintrant flares with high impact on quality of life, immunosuppressive treatment is currently used.

The major therapeutic challenges in immunosuppressive treatment for chronic skin diseases are efficacy and safety in the long-term. Furthermore, efficacy should optimally include persistent drug effect after its discontinuation. In a pragmatic approach to managing $\mathrm{AD}$ patients with chronic and severe disease, two questions can be raised: "how long can a patient remain on an immunosuppressive treatment in conditions that are both safe and efficient? (i.e. the time on drug)" and "how long can a patient be free of immunosuppressive treatment after its discontinuation? (i.e. the time between two drugs)". Drug survival analysis has recently been used to explore the first issue but data on the second issue is lacking.

Cyclosporine (CYC) and methotrexate (MTX) are the two preferred first-line immunosuppressive treatments in moderate-to-severe AD in France, probably with different treatment profiles in clinical practice. Only CYC is approved as the first-line immunosuppressive treatment for severe atopic dermatitis in France. But MTX is an off-label immunosuppressive treatment option for patients with severe atopic dermatitis. In clinical practice in France, cyclosporine and methotrexate are both the first-line immunosuppressive treatment of choice currently used for patients with atopic dermatitis requiring a first-line immunosuppressive $e^{3,4}$.

The objective of this work was to compare the treatment profiles of MTX and CYC as first-line immunosuppressive treatment in AD patients, using two survival analyses: "drug survival" and "post-drug survival” analyses. 


\section{MATERIALS AND METHODS}

\section{Study design and setting}

This retrospective longitudinal study was performed among children and adult patients with moderate-to-severe atopic dermatitis treated with at least one immunosuppressive drug, either MTX or CYC, between January 2007 and December 2016, at three French dermatology departments (Rennes University Hospital, Saint-Brieuc Hospital and Le Mans Hospital).

\section{Participants}

All patients treated with MTX or CYC as first-line immunosuppressive treatment for $\mathrm{AD}$ were included for the survival analysis.

In a first step, electronic data were used to search for patients with moderate-to-severe AD: at Rennes University Hospital, patients were selected from the biomedical database of the hospital (eHOP $)^{5}$ by entering the terms: "atopic dermatitis" or "eczema" or "atopic eczema" and "MTX" or "CYC"; at Saint-Brieuc and Le Mans Hospitals, patients were selected from the French hospital discharge database (PMSI, medicalized information system program), by using the ICD-10 code L20 "atopic dermatitis". Patients with moderate-tosevere $\mathrm{AD}$ are usually hospitalized at least once to introduce the first-line immunosuppressive treatment at Saint-Brieuc and Le Mans Hospitals.

In a second step, a total of 546 medical visit records of selected patients were read to check that MTX or CYC were given for AD at Rennes University Hospital and to select patients with MTX or CYC for AD at Saint-Brieuc and Le Mans hospitals. A total of 490 patients were excluded for the following reasons: CYC or MTX prescribed for other diseases at Rennes University Hospital ( $\mathrm{n}=274)$; no prescription of CYC or MTX for AD at SaintBrieuc et Le Mans ( $n=198)$; initiation of treatment before $2007(n=6)$; first-line systemic treatment of AD not CYC or MTX $(n=4)$; unknowm date of initiation of CYC or MTX treatment $(n=2)$; and treatment duration with MTX or CYC under 2 months $(n=6)$.

\section{Variables}

A standardized questionnaire was used to collect the following information: gender; age at initiation of first-line of immunosuppressive treatment; weight; personal and familial history of atopy; previous treatments for $\mathrm{AD}$ (anti-inflammatory topical treatments, i.e. corticosteroids and calcineurin inhibitors, or phototherapy); age at AD onset; immunosuppressive treatments following first-line immunosuppressive treatment with MTX 
or CYC (i.e. mycophenolate mofetil, azathioprine, omalizumab, intravenous immunoglobulins and alitretinoin), starting dose, maximum dose during treatment, date of start and end of each treatment line and reason for discontinuation (controlled AD, primary or secondary failure, pregnancy, non-compliance and side effects). We defined two categories of dosage for each treatment: for MTX: $\leq 15 \mathrm{mg}$ weekly and $>15 \mathrm{mg}$ weekly; and for CYC: $\leq 3.5 \mathrm{mg} / \mathrm{kg} / \mathrm{day}$ and $>3.5 \mathrm{mg} / \mathrm{kg} /$ day. For children under 12 years, a high dose of MTW was defined as $>0,25$ $\mathrm{mg} / \mathrm{kg}$ weekly. An interruption of treatment longer than three months was considered as a discontinuation of treatment. Adverse events were collected and classified as serious side effects (death, hospitalization, disability, or life-threatening consequences) and other side effects (separated into two categories of outcome: discontinuation of the treatment and continuation of treatment).

\section{Drug survival analysis}

Patients treated with MTX and CYC as first-line immunosuppressive treatment for AD were included in the "drug survival" analysis. Survival analysis is a method for analysing data for the occurrence of an event. Drug survival is the time patients remain on MTX or CYC, and the event is the discontinuation of MTX or CYC. The event date considered was the date of discontinuation of treatment whatever the reason. Time data was censored when patients were lost to follow-up or were still being treated at the end of data lock. The probability of continuing the treatment with MTX or CYC was analysed using the Kaplan-Meier method. The following possible determinants of "drug survival" for first-line immunosuppressive treatments were studied: gender, age at the initiation of first-line immunosuppressive treatment, treatment used, maximum dosage of MTX or CYC as defined below.

\section{Post-drug survival analysis}

Patients who discontinued MTX or CYC as first-line immunosuppressive treatment for AD were included in the "post-drug survival" analysis. "Post-drug survival" was defined as the time between the end of the first-line immunosuppressive treatment with MTX or CYC and the second-line immunosuppressive treatment (time between two drugs). The event date considered was the date of initiation of the second-line immunosuppressive treatment. Time was censored when patients were lost to follow-up or did not start a second-line immunosuppressive treatment at the end of data lock. The probability of starting second-line immunosuppressive treatment after the discontinuation of first-line immunosuppressive treatment was analysed using the Kaplan-Meier method. The following possible determinants 
of "post-drug survival" were studied: age at onset of disease, gender, long duration of firstline treatment, treatment used, high dose of the first-line treatment, and discontinuation of the first-line treatment because the disease was under control. "Drug survival" and "post-drug survival" are presented in Fig. 1.

\section{Statistical analyses}

Drug survival was analyzed using the Kaplan-Meier survival curves. Two survival curves were defined and analyzed separately: the date of treatment discontinuation (providing "drug survival") and the date of initiation of the second-line treatment after discontinuation of MTX or CYC (providing "post-drug survival”). Differences in drug survival between the two groups were analyzed using the log-rank test. A descriptive analysis of qualitative data was performed, calculating numbers and percentages for each category, while quantitative data was described by calculating means, minimum and maximum values. We performed Cox regression analysis to identify predictive determinants for "drug survival" and "post-drug survival". The variables with a $p$-value $<0.2$ in the univariate analysis were entered into the multivariate model. A $p$-value under 0.05 was considered significant. Analyses were stratified according to center. The $\chi^{2}$ test was used to compare the reasons for treatment discontinuation. Statistical analyses were performed with $\mathrm{R}$ software version 3.3.0.

The study was approved by Ethics Committee of Rennes University Hospital ( $\left.\mathrm{n}^{\circ} 17.32\right)$ and patients gave their signed informed consent for the anonymous use of their medical information in the context of a medical research, in accordance with the principles of the Helsinki Declaration.

\section{RESULTS}

\section{Patients and treatment characteristics}

In all, 56 patients with moderate-to-severe AD treated with CYC or MTX as first-line immunosuppressive treatment were included between 2007 and 2016. The baseline characteristics of these patients are shown in Table 1 . The mean age of patients was $34 \pm 15$ years and the gender ratio was $1: 1$. For $89 \%$ of patients, the onset of $\mathrm{AD}$ occurred during childhood. All patients received topical anti-inflammatory treatments including topical steroids and topical calcineurin inhibitors; $57 \%$ of the patients were treated with phototherapy. In addition, $62 \%$ of the patients had been hospitalized for $\mathrm{AD}$, including 9 patients for serious skin infections. 
Among the 56 patients with moderate-to-severe AD treated with CYC or MTX as first-line immunosuppressive treatment, 25 patients (44.6\%) received $\mathrm{CYC}$ and 31 patients $(55.4 \%)$ received MTX. The mean starting dose was $2.2 \pm 0.63 \mathrm{mg} / \mathrm{kg}$ daily for CYC $(\mathrm{n}=24)$ and $11 \pm$ $3.63 \mathrm{mg}$ weekly for MTX $(\mathrm{n}=30)$. The mean maximum dose during treatment was $3.6+/-1.25$ $\mathrm{mg} / \mathrm{kg}$ daily for CYC $(\mathrm{n}=22)$ and $16 \pm 4.59 \mathrm{mg}$ weekly for MTX $(\mathrm{n}=28)$. The details are given in the supplementary data.

The Sankey diagram shows the different sequences of first, second, third and subsequent courses of immunosuppressive treatments for the 56 patients with moderate-tosevere AD treated with CYC or MTX as a first-line immunosuppressive treatment (Fig. 2).

At the end of data collection, 18 patients treated with MTX and 20 patients treated with CYC had discontinued the first-line immunosuppressive treatment. The reasons for discontinuation of the first-line immunosuppressive treatments are presented in Table 2 . The causes of discontinuation were obtained for 17 patients receiving MTX and 14 patients receiving CYC. Ten patients (55\%) treated with MTX and 3 patients (16\%) treated with CYC discontinued the treatment for controlled disease. Four patients $(22 \%)$ treated with MTX and 6 patients $(31 \%)$ treated with CYC discontinued the treatment following either primary or secondary failure. Only $3(16 \%)$ patients discontinued CYC because of side effects (not serious) and no patient discontinued MTX because of side effects. There was no difference between cyclosporine and methotrexate for the reasons of treatment discontinuation ("controlled disease" and other reasons) ( $p$-value $=0.11)$.

\section{Drug survival}

Comparison of drug survival for MTX and CYC as first-line immunosuppressive treatments.

The comparison of drug survival between MTX and CYC using Kaplan-Meier curves is presented in Fig. 3. The median drug survival for CYC and MTX as first-line treatment was 8 and 23 months respectively ( $\log$ rank $\mathrm{p}<0.0001)$. Six months after initiation of MTX, 93\% of patients were still being treated versus $60 \%$ of patients on CYC. Twelve months after the initiation of MTX, $71 \%$ of patients were still being treated versus $38 \%$ of patients on CYC. 
Table 3 shows the determinants of drug survival for MTX and CYC as first-line immunosuppressive treatment according to univariate and multivariate Cox regression analyses. There was no association between drug survival for MTX or CYC and age at initiation of treatment, gender and a high doses of MTX or CYC. CYC was the only predictive factor for shorter drug survival in univariate and multivariate models (HR 7.44; 95\% CI 1.97-28.13; $<<0.003)$.

\section{Post-drug survival}

Comparison of post drug survival for MTX and CYC as first-line immunosuppressive treatments

Thirty-eight patients discontinued the first-line immunosuppressive treatment $(\mathrm{n}=18$ for MTX; $n=20$ for CYC). The median duration of "post-drug survival" was 12 months for MTX and 2 months for CYC (log rank $p=0.014$ ) (Fig. 4). Six months after discontinuation of MTX, $28 \%$ of the patients required a second-line treatment, whereas $75 \%$ required it after discontinuation of CYC.

Six months after discontinuation because of disease control $(n=10$ for MTX and $n=5$ for CYC), no patient required second-line treatment after first-line immunosuppressive treatment with MTX versus $75 \%$ of patients after first-line treatment with CYC (log rank $p=0.5$ ). Six months after discontinuation for other reasons ( $\mathrm{n}=8$ for MTX and $\mathrm{n}=15$ for CYC), $50 \%$ of the patients required second-line treatment after first-line immunosuppressive treatment with MTX versus $80 \%$ of patients after CYC $(\log \operatorname{rank} p=0.13)$.

Table 4 shows the determinants of "post-drug survival" in univariate and multivariate Cox regression analyses. A long duration of the first-line treatment (HR=1.13; IC95\% $(0.46-$ $2.76) ; p=0.79$ ) and discontinuation of the first-line immunosuppressive treatment following disease control $(\mathrm{HR}=0.76$; IC95\% $(0.26-2.19) ; p=0.60)$ were not associated with a shorter time between two drugs ("post-drug survival"). CYC was the only predictive factor for shorter "post-drug survival" $(\mathrm{HR}=3.00 ; \mathrm{IC} 95 \%(0.83-10.89) ; p=0.09)$. 


\section{DISCUSSION}

This is the first direct comparison in daily practice between MTX and CYC in moderate-to-severe $\mathrm{AD}$ as first-line immunosuppressive treatments. Further to this, we were able to describe two treatment profiles using an approach based on "drug survival" (time on drug) and "post-drug survival" (time between two drugs). "Drug survival" was significantly longer for MTX (median=23 months) than for CYC (median=8 months) and "post-drug survival" was also significantly longer for MTX (median=12 months) than for CYC (median= 2 months).

Comparative studies between two common systemic treatments in $\mathrm{AD}$ are a major research priority and a concern for clinicians ${ }^{6}$, as highlighted by a recent systematic review ${ }^{7}$. A recently published phase 3 randomized non-inferiority study comparing MTX at $15 \mathrm{mg}$ weekly and CYC at $2.5 \mathrm{mg} / \mathrm{kg} / \mathrm{d}$ showed a rapid onset of CYC efficacy with a larger proportion of patients achieving SCORAD 50 at 8 weeks (42\% vs $8 \%$ ). Increasing the dose of MTX to $25 \mathrm{mg}$ weekly resulted in a similar clinical improvement to that obtained with high doses of CYC of $5 \mathrm{mg} / \mathrm{kg} / \mathrm{d}$ at week $20^{8}$. A pediatric study of forty children suggested similar treatment responses between $\mathrm{CYC}$ and $\mathrm{MTX}^{9}$. There is at present one multicentric randomized controlled trial in the UK comparing MTX and CYC among children with moderate-to-severe $\mathrm{AD}^{10}$.

The efficacy and safety results of these clinical trials are difficult to generalize to patients in daily practice settings because of strict inclusion criteria. Clinical studies often include better-fitted and more compliant patients. The severity profile of patients in trials is also different and does not reflect indications for treatment in daily clinical practice. For instance, Goujon et al. study included a severe profile of patients $(80 \%$ of patients with baseline SCORAD index $>40$ ), resulting in early treatment discontinuations. Retrospective studies in real-life settings in $\mathrm{AD}$ are complementary to clinical studies, providing additional information such as duration of treatment, the hierarchy of common treatments used in clinical practice and the prevalence of side events in "real world" patients with more comorbidities than in clinical trials. Few studies have been conducted in $\mathrm{AD}^{11,12}$. Knowledge in these fields can be helpful in clinical decision-making in addition to clinical trials. The present study gives objective information about the time on MTX and CYC, which are both immunosuppressive treatments commonly used in daily practice for the treatment of 
moderate-to-severe AD. The comparison for "drug survival" and "post-drug survival" evidences significant differences between MTX and CYC in AD, suggesting their different treatment profiles.

Unlike studies on efficacy, disease activity scores are not widely used in daily practice for the assessment of AD disease. Drug survival analysis, which concerns time on treatment, is an objective and informative outcome, especially for retrospective studies. Events that lead to withdrawal of a treatment are also informative, such as effectiveness, failure and side events. Therefore, drug survival analysis is increasingly used to assess long-term and chronic treatments such as biotherapies in rheumatology and dermatology ${ }^{13,14}$. Long drug survival is assumed to attest of an adequate balance between efficacy and safety for both clinicians and patients. Drug survival analysis is also useful to identify predictive factors for long duration of treatment.

It can also be of interest to analyze the time patients remain without treatment until a subsequent line of immunosuppressive treatment is required in chronic diseases. Indeed, treatment discontinuation often occurs in chronic skin diseases without the need for a switch of treatment, especially in AD. "Post-drug survival" is a new approach that includes both the benefit of the first-line immunosuppressive treatment and the time free from any immunosuppressive treatment, which is a main concern for patients.

Some limitations to this study should be discussed. It is a retrospective study with a small sample size. It is also limited by some missing data concerning the causes of treatment discontinuation. Retrospective screening in medical records implies an information bias, but a uniform and extensive search was performed to minimize it.

The median "drug survival" of 8 months for CYC reported here is consistent with two recent drug survival studies ${ }^{15,16}$. In contrast, the median "drug survival" for MTX is estimated at 23 months in this study, more than twice a previous result ${ }^{17}$. The drug survival for MTX is significantly longer than for CYC. This finding could be explained by a particular immumodulatory effect of MTX, a use of MTX for less severe AD, or a different safety profile between MTX and CYC. MTX discontinuation because of side events was not reported in this study. The shorter time on the drug for CYC could suggest rapid efficacy on AD. However long-term CYC use is restricted by safety concerns, including potential 
nephrotoxicity and risk of skin cancer, with a treatment duration usually between 9 and 12 months ${ }^{18,19}$. "Drug survival" can be influenced by various factors: the physician's prescribing behaviors, patient satisfaction, comorbidities, safety profile of the treatment, effectiveness, and availability of alternative treatments ${ }^{13}$.

As regards the causes of MTX and CYC discontinuation, the proportion of discontinuations for "disease under control" among patients treated with CYC is lower in the present study than in others $(16 \% \text { vs } 22 \% \text { and } 45 \%)^{15,16}$ while the proportion of discontinuations for "disease under control" for patients with MTX is in line with previous findings (55\% vs 49\%) ${ }^{17}$. This could suggest a higher severity profiles among patients treated with CYC in our population. The interpretation of the result is limited by the small number of reasons for discontinuation of the first-line treatment.

"Post-drug survival", which relates to the probability of starting a second line of treatment after withdrawal of a first treatment, has not been studied in $\mathrm{AD}$, and is a major concern for physicians and patients. The result evidencing a shorter "post-drug survival" for CYC (median= 2 months) than for MTX (median= 12 months) could suggest a suspensive effect of CYC without a maintenance effect in the long-term, a more severe disease profile in patients treated with $\mathrm{CYC}$, or treatment discontinuation because of a serious side effect. "Post-drug survival" can be influenced by a remanence effect of the first-line treatment, by patient or physician decision to start a subsequent treatment, by duration and dosage of the previous treatment or by the availability of efficient alternative treatments. "Post-drug survival" could reflect "time to relapse" which has already been studied in studies on CYC in $\mathrm{AD}^{20,21}$. However, the definition of "relapse" mainly depends on the measurement of disease activity, which is often difficult to obtain in retrospective studies, whereas "post-drug survival" is easily measurable and remains an objective outcome.

The differences in drug survival and post-drug survival between CYC and MTX point to two treatment profiles: on the one hand, the effect of MTX tends to correspond to immunomodulatory treatment, compared to CYC where the effect is more suspensive. Managing severe AD requiring immunosuppressive treatments is difficult. Recent guidelines have proposed a strategy to help the physician's clinical decision to initiate an immunosuppressive treatment for chronic and refractory $\mathrm{AD}^{22}$. However, no recommendation on the withdrawal of an immunosuppressive treatment in $\mathrm{AD}$ is provided. Indeed, the 
assessment of this disease is complex: clinical skin scores are used in clinical trials but are too time-consuming for the physicians in clinical practice, and they are static measurements of severity not taking account of the overall course of $\mathrm{AD}$, with flares and sometimes spontaneous remissions. Drug survival studies are expanding in the field of management of chronic disease. We suggest including "post-drug survival" for the purpose of better assessment in the use of immunosuppressive treatments, particularly in chronic skin diseases. Taking account both approaches, "drug survival" and "post-drug survival", our findings suggest that MTX may present a better treatment profile for the long term control of moderate-to-severe $\mathrm{AD}$, which is a well-identified challenge for clinical research and care ${ }^{23}$.

This is the first direct comparison of MTX and CYC in moderate-to-severe AD in daily practice using "drug survival", and a new concept of "post-drug survival". Two treatment profiles have been identified: treatment duration of MTX is longer than that of CYC and the time to initiation of a new treatment is also longer after MTX withdrawal. "Post-drug survival" could be a new tool for better assessment of the maintenance effect after immunosuppressive treatment discontinuation in chronic skin disease.

\section{ACKNOWLEDGMENTS}

The English text has been edited by Angela Verdier.

\section{REFERENCES}

1. Silverberg JI, Hanifin JM. Adult eczema prevalence and associations with asthma and other health and demographic factors: A US population-based study. J Allergy Clin Immunol. 2013 Nov;132(5):1132-8.

2. Kim JP, Chao LX, Simpson EL, Silverberg JI. Persistence of atopic dermatitis (AD): A systematic review and meta-analysis. J Am Acad Dermatol. 2016 Oct 1;75(4):681-687.e11.

3. Wollenberg A, Oranje A, Deleuran M, Simon D, Szalai Z, Kunz B, et al. ETFAD/EADV Eczema task force 2015 position paper on diagnosis and treatment of atopic dermatitis in adult and paediatric patients. J Eur Acad Dermatol Venereol. 2016 May;30(5):729-47.

4. Totri CR, Eichenfield LF, Logan K, Proudfoot L, Schmitt J, Lara-Corrales I, et al. Prescribing practices for systemic agents in the treatment of severe pediatric atopic dermatitis in the US and Canada: The PeDRA TREAT survey. J Am Acad Dermatol. 2017 
Feb;76(2):281-5.

5. Bouzillé G, Sylvestre E, Campillo-Gimenez B, Renault E, Ledieu T, Delamarre D, et al. An Integrated Workflow For Secondary Use of Patient Data for Clinical Research. Stud Health Technol Inform. 2015;216:913.

6. Taylor K, Swan DJ, Affleck A, Flohr C, Reynolds NJ, in collaboration with the U.K. Translational Research Network in Dermatology and the U.K. Dermatology Clinical Trials Network. Treatment of moderate-to-severe atopic eczema in adults within the U.K.: results of a national survey of dermatologists. Br J Dermatol. 2017 Jun;176(6):1617-23.

7. Nankervis H, Thomas KS, Delamere FM, Barbarot S, Smith S, Rogers NK, et al. What is the evidence base for atopic eczema treatments? A summary of published randomized controlled trials. Br J Dermatol. 2017 Apr;176(4):910-27.

8. Goujon C, Viguier M, Staumont-Sallé D, Bernier C, Guillet G, Lahfa M, et al. Methotrexate Versus Cyclosporine in Adults with Moderate-to-Severe Atopic Dermatitis: A Phase III Randomized Noninferiority Trial. J Allergy Clin Immunol Pract. 2017 Sep 26;

9. El-Khalawany MA, Hassan H, Shaaban D, Ghonaim N, Eassa B. Methotrexate versus cyclosporine in the treatment of severe atopic dermatitis in children: a multicenter experience from Egypt. Eur J Pediatr. 2013 Mar;172(3):351-6.

10. TREAT, http://www.treat-trial.org.uk/index.html, n.d. (accessed 11 February 2017).

11. Védie A-L, Ezzedine K, Amazan E, Boralevi F, Milpied B, Taïeb A, et al. Long-term Use of Systemic Treatments for Moderate-to-Severe Atopic Dermatitis in Adults: A Monocentric Retrospective Study. Acta Derm Venereol. 2016 Aug 23;96(6):802-6.

12. Garritsen FM, Roekevisch E, van der Schaft J, Deinum J, Spuls PI, de Bruin-Weller MS. Ten years experience with oral immunosuppressive treatment in adult patients with atopic dermatitis in two academic centres. J Eur Acad Dermatol Venereol. 2015 Oct;29(10):1905-12.

13. van den Reek JMPA, Kievit W, Gniadecki R, Goeman JJ, Zweegers J, van de Kerkhof PCM, et al. Drug Survival Studies in Dermatology:Principles, Purposes, and Pitfalls. J Invest Dermatol. 2015 Jul;135(7):1-5.

14. Menter A, Papp K a., Gooderham M, Pariser D m., Augustin M, Kerdel F a., et al. Drug survival of biologic therapy in a large, disease-based registry of patients with psoriasis: results from the Psoriasis Longitudinal Assessment and Registry (PSOLAR). J Eur Acad Dermatol Venereol. 2016 Jul 1;30(7):1148-58.

15. van der Schaft J, Politiek K, van den Reek JMPA, Christoffers WA, Kievit W, de Jong EMGJ, et al. Drug survival for ciclosporin A in a long-term daily practice cohort of adult patients with atopic dermatitis. Br J Dermatol. 2015 Jun;172(6):1621-7.

16. Daguzé J, Aubert H, Bernier C, Gaultier A, Nguyen J-M, Stalder J-F, et al. A Monocentric Retrospective Cohort of Patients with Severe Atopic Dermatitis Treated with Cyclosporine A in Daily Practice. Acta Derm Venereol. 2017 Aug 31;97(8):955-6. 
17. Politiek K, van der Schaft J, Coenraads PJ, de Bruin-Weller MS, Schuttelaar MLA. Drug survival for methotrexate in a daily practice cohort of adult patients with severe atopic dermatitis. Br J Dermatol. 2016 Jan;174(1):201-3.

18. Vercauteren SB, Bosmans JL, Elseviers MM, Verpooten GA, De Broe ME. A metaanalysis and morphological review of cyclosporine-induced nephrotoxicity in auto-immune diseases. Kidney Int. 1998 Aug;54(2):536-45.

19. Paul CF, Ho VC, McGeown C, Christophers E, Schmidtmann B, Guillaume J-C, et al. Risk of malignancies in psoriasis patients treated with cyclosporine: a $5 \mathrm{y}$ cohort study. $\mathrm{J}$ Invest Dermatol. 2003 Feb;120(2):211-6.

20. Granlund H akan, Erkko P, Sinisalo M, Reitamo S. Cyclosporin in atopic dermatitis: time to relapse and effect of intermittent therapy. Br J Dermatol. 1995;132(1):106-112.

21. Harper J i., Ahmed I, Barclay G, Lacour M, Hoeger P, Cork M j., et al. Cyclosporin for severe childhood atopic dermatitis: short course versus continuous therapy. Br J Dermatol. 2000 Jan 1;142(1):52-8.

22. Simpson EL, Bruin-Weller M, Flohr C, Ardern-Jones MR, Barbarot S, Deleuran M, et al. When does atopic dermatitis warrant systemic therapy? Recommendations from an expert panel of the International Eczema Council. J Am Acad Dermatol. 2017 Oct;77(4):623-33.

23. Chalmers JR, Schmitt J, Apfelbacher C, Dohil M, Eichenfield LF, Simpson EL, et al. Report from the third international consensus meeting to harmonise core outcome measures for atopic eczema/dermatitis clinical trials (HOME). Br J Dermatol. 2014 Dec;171(6):131825 .

Table 1. Patient characteristics

\begin{tabular}{|l|l|l|l|}
\hline Patient characteristics at baseline & $\begin{array}{l}\text { Overall } \\
\text { population } \\
(\mathrm{N}=56)\end{array}$ & $\begin{array}{l}\text { Patients treated } \\
\text { with MTX } \\
(\mathrm{N}=31)\end{array}$ & $\begin{array}{l}\text { Patients treated } \\
\text { with CYC } \\
(\mathrm{N}=25)\end{array}$ \\
\hline $\begin{array}{l}\text { Age at initiation of the first-line systemic treatment - } \\
\text { year }\end{array}$ & $34 \pm 15$ & $35 \pm 15$ & $32 \pm 16$ \\
\hline Male gender - no. (\%) & $28(50)$ & $14(45)$ & $14(56)$ \\
\hline $\begin{array}{l}\text { Personal history of atopy - no. (\%) } \\
\text { Asthma ( }=44)\end{array}$ & $38(86)$ & $20(83)$ & $18(90)$ \\
\hline Rhinitis ( $=37)$ & $20(54)$ & $9(50)$ & $11(58)$ \\
\hline Food allergy $(\mathrm{n}=23)$ & $13(56)$ & $4(40)$ & $9(69)$ \\
\hline Conjunctivitis $(\mathrm{n}=37)$ & $14(38)$ & $4(23)$ & $10(50)$ \\
\hline Keratoconus $(\mathrm{n}=1)$ & $1(100)$ & $0(0)$ & $1(100)$ \\
\hline
\end{tabular}




\begin{tabular}{|c|c|c|c|}
\hline Family history of atopy $(\mathrm{n}=43)-$ no. $(\%)$ & $20(46)$ & $9(41)$ & $11(52)$ \\
\hline \multicolumn{4}{|l|}{ Age at onset of $A D(\mathrm{n}=46)-$ no. $(\%)$} \\
\hline $0-9$ years & $41(89)$ & $21(84)$ & $20(95)$ \\
\hline $10-18$ years & $2(4)$ & $1(4)$ & $1(5)$ \\
\hline $19-35$ years & $2(4)$ & $2(8)$ & $0(0)$ \\
\hline$>35$ years & $1(2)$ & $1(4)$ & $0(0)$ \\
\hline $\begin{array}{l}\text { Serious infection (defined as requiring hospitalization) } \\
(\mathrm{n}=46)-\text { no. }(\%)\end{array}$ & $9(20)$ & $5(18)$ & $4(21)$ \\
\hline \multicolumn{4}{|l|}{ Comorbidities - no. $(\%)$} \\
\hline Cardiovascular $(\mathrm{n}=9)$ & $3(33)$ & $2(28)$ & $1(50)$ \\
\hline Obesity $(n=9)$ & $1(11)$ & $1(14)$ & $0(0)$ \\
\hline \multicolumn{4}{|l|}{ Previous treatments - no. (\%) } \\
\hline \multicolumn{4}{|l|}{ Phototherapy $(\mathrm{n}=32)$} \\
\hline \multicolumn{4}{|l|}{ Total sessions $(\mathrm{n}=21)$} \\
\hline$<10$ & $2(9)$ & $1(10)$ & $1(9)$ \\
\hline 10 à 19 & $9(43)$ & $3(30)$ & $6(55)$ \\
\hline 20 à 39 & $4(19)$ & $2(20)$ & $2(18)$ \\
\hline 40 à 59 & $4(19)$ & $2(20)$ & $2(18)$ \\
\hline 60 à 79 & $1(5)$ & $1(10)$ & $0(0)$ \\
\hline 80 à 100 & $1(5)$ & $1(10)$ & $0(0)$ \\
\hline \multicolumn{4}{|l|}{ Type of phototherapy $(n=22)$} \\
\hline UVA1 & $1(5)$ & $1(10)$ & $0(0)$ \\
\hline UVBTLO1 & $15(68)$ & $5(50)$ & $10(83)$ \\
\hline PUVA & $3(13)$ & $3(30)$ & $0(0)$ \\
\hline Other & $3(13)$ & $1(10)$ & $2(17)$ \\
\hline Hospitalization for $\mathrm{AD}(\mathrm{n}=32)-$ no. $(\%)$ & $20(62)$ & $7(54)$ & $13(68)$ \\
\hline
\end{tabular}

All percentages are given for patients with data available 
Table 2. Reasons for discontinuation of the first-line immunosuppressive treatment.

\begin{tabular}{|c|c|c|c|}
\hline $\begin{array}{l}\text { Reasons of discontinuation of the first-line } \\
\text { immunosuppressive therapy }\end{array}$ & MTX & CYC & $p$-value \\
\hline & $\mathrm{N}=18(\%)$ & $\mathrm{N}=20(\%)$ & \multirow{8}{*}{0.11} \\
\hline Controlled AD & $10(56)$ & $3(16)$ & \\
\hline Primary failure & $2(11)$ & $4(21)$ & \\
\hline Secondary failure & $2(11)$ & $2(10)$ & \\
\hline Side effects & $\begin{array}{ll}0 & (0)\end{array}$ & $3(16)$ & \\
\hline Non-compliance & $1 \quad(6)$ & $1(5)$ & \\
\hline Pregnancy & $2(11)$ & $1(5)$ & \\
\hline Unknown & $1 \quad(6)$ & $6(30)$ & \\
\hline
\end{tabular}

Table 3. Determinants of "drug survival" of first-line immunosuppressive treatment by univariate and multivariate Cox regression analysis.

Univariate model $\quad$ Multivariate model

\begin{tabular}{lllllll}
\hline Variable & HR & $\mathbf{9 5 \%}$ CI & $\boldsymbol{p}$ & HR & $\mathbf{9 5 \%}$ CI & $\boldsymbol{p}$ \\
\hline Age* & 0.98 & $0.96-1.00$ & 0.11 & 0.97 & $0.94-1.00$ & 0.14 \\
Gender† & 1.12 & $0.56-2.28$ & 0.74 & 1.38 & $0.56-3.38$ & 0.48 \\
Drug CYC (ref : MTX) & 9.20 & $3.04-27.80$ & $<0.001$ & 7.44 & $1.97-28.13$ & 0.003 \\
High dose of treatment; & 1.99 & $0.86-4.65$ & 0.11 & 0.68 & $0.24-1.96$ & 0.48
\end{tabular}

* At the initiation of the first-line treatment

$\dagger$ Male as reference

$\ddagger$ Defined as a mean maximum dose of CYC $>3.5 \mathrm{mg} / \mathrm{kg}$ daily, MTX $>15 \mathrm{mg}$ weekly and for children under 12 years old, MTX $>0,25 \mathrm{mg} / \mathrm{kg}$ weekly

Analysis stratified according to center. Data are given as hazard ratios (HR) (95\% confidence interval). 
Table 4. Determinants of "post-drug survival" for first-line immunosuppressive treatment by univariate and multivariate Cox regression analysis.

\begin{tabular}{|c|c|c|c|c|c|c|}
\hline \multirow[b]{2}{*}{ Variable } & \multicolumn{3}{|c|}{ Univariate analysis } & \multicolumn{3}{|c|}{ Multivariate } \\
\hline & HR & $95 \% \mathrm{CI}$ & $p$ & HR & 95\%CI & $p$ \\
\hline Age* & 1.03 & $0.99-1.08$ & 0.12 & 1.04 & $0.99-1.09$ & 0.06 \\
\hline Gender $\dagger$ & 1.94 & $0.66-5.70$ & 0.22 & - & - & - \\
\hline Long duration of first-line treatment + & 1.13 & $0.46-2.76$ & 0.79 & - & - & - \\
\hline Drug CYC (ref : MTX) & 2.42 & $0.69-8.50$ & 0.17 & 3.00 & $0.83-10.89$ & 0.09 \\
\hline High dose of treatment $\S$ & 1.19 & $0.37-3.82$ & 0.77 & - & - & - \\
\hline $\begin{array}{l}\text { Discontinuation of first-line treatment } \\
\text { because of controlled disease }\end{array}$ & 0.76 & $0.26-2.19$ & 0.60 & - & - & - \\
\hline
\end{tabular}

*At the initiation of the first-line treatment

$\dagger$ Male as reference

† Defined as a duration of treatment $>12$ months for MTX and $>6$ months for CYC

$\S$ Defined as a mean maximum dose over treatment with CYC $>3.5 \mathrm{mg} / \mathrm{kg}$ daily, MTX $>15 \mathrm{mg}$ weekly and for children under 12 years old, MTX $>0,25 \mathrm{mg} / \mathrm{kg}$ weekly

Analysis stratified according to center. Data are given as hazard ratios (HR) (95\% confidence interval). 
Figure 1. Definition of "drug survival" and "post-drug survival".

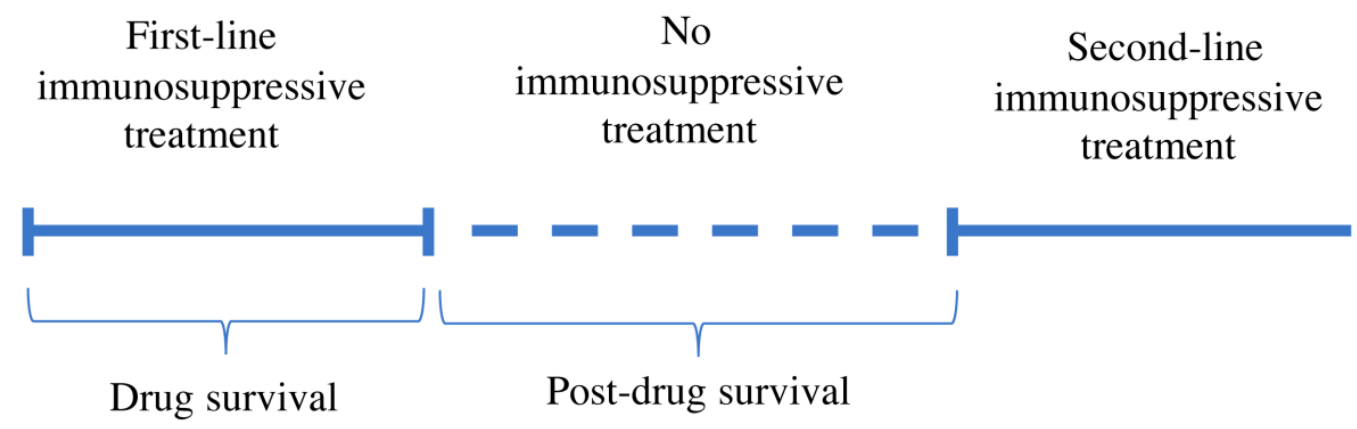

Figure 2. Sequences of treatment lines for immunosuppressive treatments: Sankey diagram

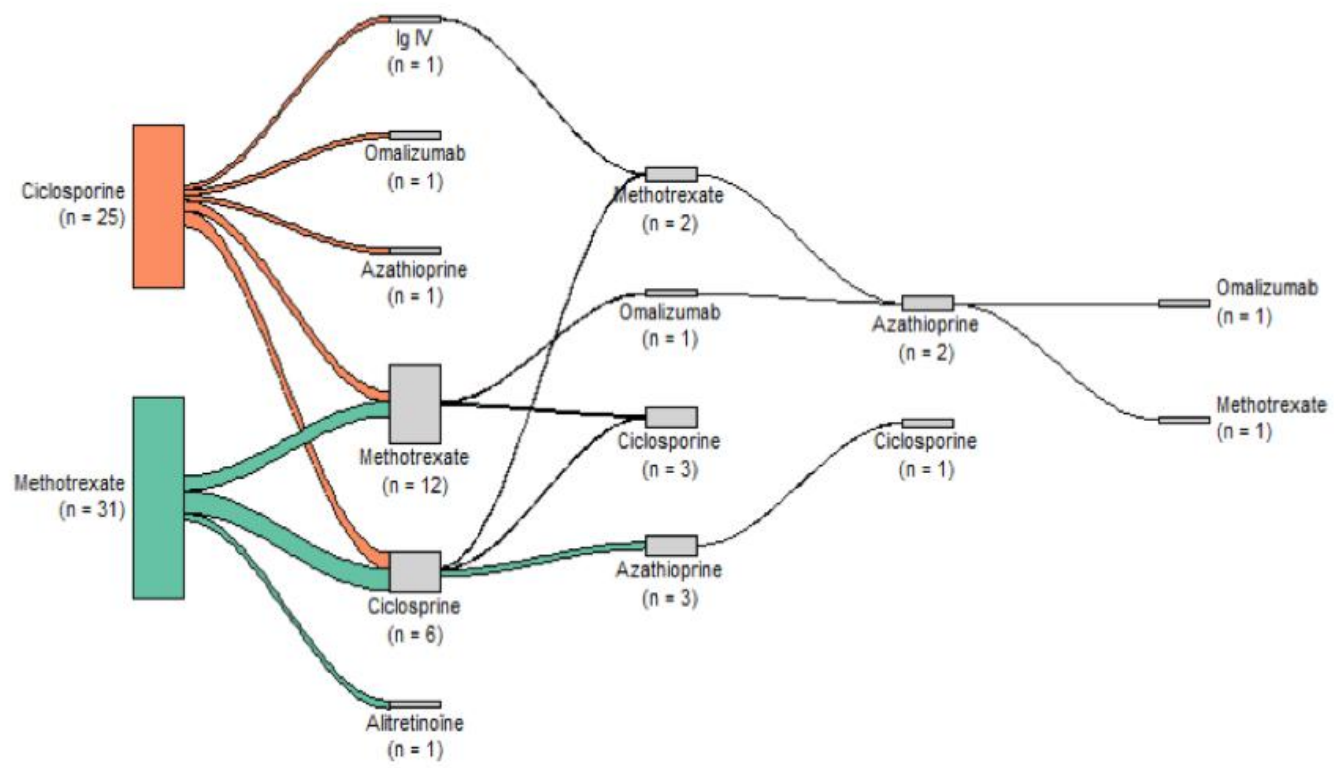

All the drugs presented in the same column belong to the same line of treatment. The height of the boxes and the thickness of the lines are porportional to the number of patients. Durations and interruptions are not represented. 
Figure 3. Comparison of "drug survival" for cyclosporine (CYC) and methotrexate (MTX) as first-line immunosuppressive treatment for atopic dermatitis.

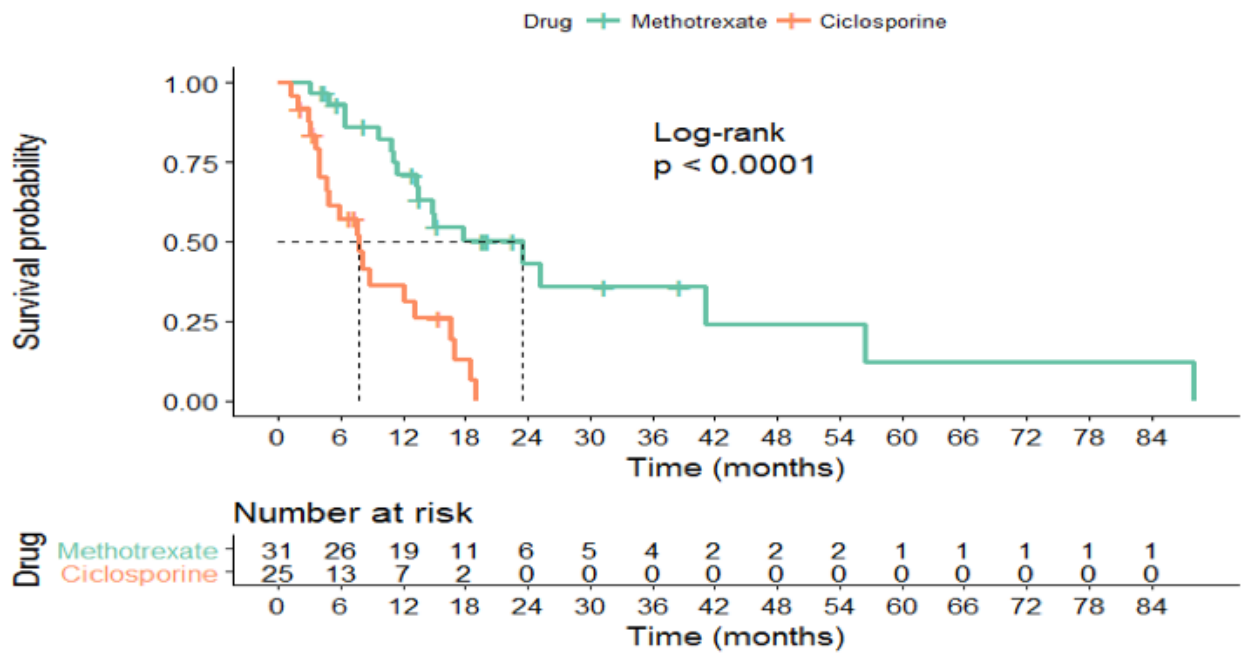

The probability of continuing the first-line immunosuppressive treatment was analysed using the Kaplan-Meier method. 
Figure 4. Comparison of "post-drug survival" for cyclosporine (CYC) and methotrexate (MT) as first-line immunosuppressive treatment for atopic dermatitis.
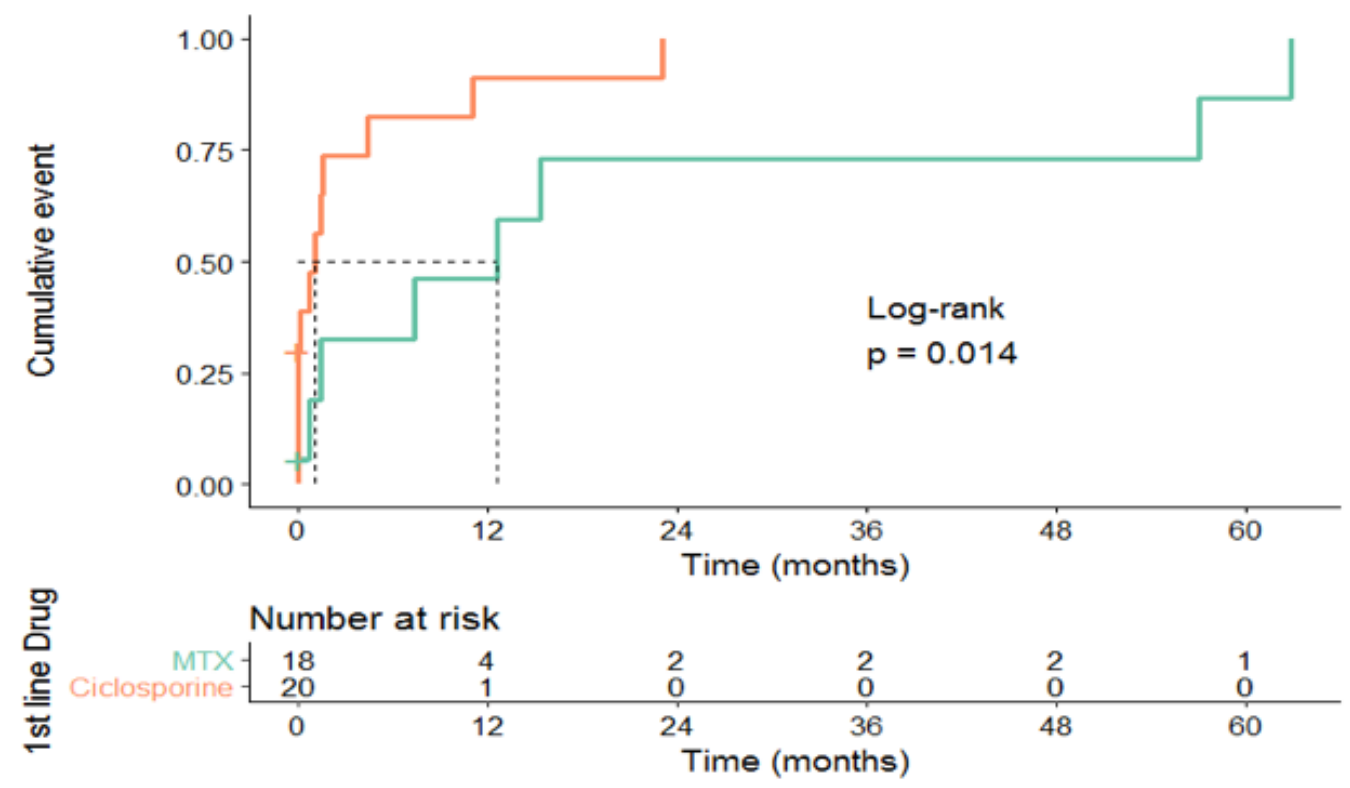

The probability of starting the second-line immunosuppressive treatment after the discontinuation of MTX and CYC was analysed using the Kaplan-Meier method. 